\title{
AS PAISAGENS COEXISTENCIAIS INTERESPECÍFICAS, OU SOBRE \\ HUMANOS E NÃO-HUMANOS COMPARTILHANDO ESPAÇOS \\ DOMÉSTICOS NUMA CIDADE AMAZÔNICA
}

Flávio Leonel Abreu da Silveira ${ }^{1}$

\section{À guisa de introdução}

A proposta deste artigo é a de refletir sobre as complexas interações entre humanos e não-humanos no contexto das cidades, considerando a dimensão coexistencial das paisagens urbanas abarcadoras de nichos (ecológicos, tróficos, espaciais) ocupados por distintos não-humanos em interação com os coletivos humanos, seja na ordem da interioridade da casa, no seu entorno (especialmente os quintais e jardins) ou nos espaços considerados como públicos, como os bairros e as áreas verdes urbanas. Nestes termos, volto-me especialmente à casa humana, concebendo a morada e a sua domesticidade não apenas como o resultado ético-estético do habitar, mas também como o locus agregador de tais nichos a partir da humanização difusa dos espaços, onde a plasticidade adaptativa das espécies que coexistem com os humanos revela as dinâmicas das paisagens urbanas. Sendo assim, (re)visito uma ampla bibliografia a fim de construir meus argumentos para pensar a interespeciedade na urbe como um fenômeno contemporâneo, o que por si só define o caráter interdisciplinar da minha empreitada.

\section{Perspectiva ecosófica e coexistencial: por uma interespeciedade na urbe}

O debate acerca das interações entre humanos e não-humanos parece estar na ordem do dia, principalmente quando se refere ao convívio mais ou menos tenso entre pessoas e animais no mundo urbano, fenômeno este que os antropólogos tem se defrontado quando refletem sobre as relações interespécies que ocorrem no cotidiano das grandes cidades brasileiras. O tema, todavia, não diz respeito apenas às espécies de companhia (pets) cuja presença no âmbito da domesticidade dos lares é um fenômeno

\footnotetext{
${ }^{1}$ Universidade Federal do Pará, Brasil.
} 
bastante comum no mundo urbano contemporâneo, ainda que ele mereça ser mais bem compreendido para os casos brasileiro e amazônico.

As interações ecológicas que entrelaçam humanos e animais, no entanto, abarcam uma ecossistêmica complexa, uma vez que também abrangem aquelas espécies de vida livre que habitam a cidade, as quais ocupam nichos espaciais (e tróficos) que implicam níveis de adaptabilidade, por vezes, surpreendentes. Tais seres precisam lidar com os artefatos humanos e, mesmo, com os espaços de sociabilidade humana, como é o caso dos parques de lazer, dos jardins zoológicos - neste caso, coexistindo com animais de cativeiro - e botânicos, além, é claro, das áreas verdes voltadas à conservação da vida silvestre presentes no espaço urbano, especialmente quando se pensa a importância do tema para as sociedades modernas urbano-industriais.

Se partirmos do pressuposto de que o contexto urbano, seja ele qual for, constitui um conjunto complexo de ambientes (e ambiências) altamente manejados pelos humanos devido as suas agências nas paisagens que constituem a cidade, percebemos que tanto as suas ações técnico-culturais modeladoras do meio quanto as agências nãohumanas - animais; vegetais; dinâmicas climáticas e assim por diante - interferem e cooperam na configuração dos lugares praticados (Certeau, 1994), entendidos como paisagens de pertença (sócio e biodiversas). O humano, neste caso, afeta e é afetado (Favret-Saada, 2005) pelo meio: ele constitui a paisagem à medida que é constituído por ela (Silveira, 2009a).

A cidade planejada estaria, neste caso, desde uma visão racionalista e construtivista, constituída por espaços voltados às ordens formais pautadas no domínio de técnicas/tecnologias que (re)definiriam constantemente as feições da urbe - uma série de projetos/de equipamentos sociotécnicos relativos a um tipo específico de ecologia humana intrínseca à vida neste contexto -, envolvendo critérios de ocupação, de regulação, de edificação, entre outros, voltados ao corpus urbano.

Todavia a urbe, como um construto humano, segue os seus desígnios. Ela está aberta às vicissitudes e aos imponderáveis inerentes a sua dinâmica pulsante, os quais apontam para o fato de que para além de certos dispositivos de controle sobre as formas do vivo (Rabinow e Rose, 2006) presentes em seu contexto - mediante as estratégias de biopoder que visam políticas de domínio sobre os ditos elementos naturais, voltadas ao bem-estar humano e à conformação de paisagens praticáveis - existe em tal processo uma autonomia das/nas paisagens que tem relação direta com dimensões biogeográficas 
e sazonais ${ }^{2}$ que, por certo, também (re)definem os seus constituintes de acordo com a região e o contexto onde aparecem como elementos em interação com o edificado e, por isso, mostrando-se em constante permuta tanto de matérias quanto de energias.

Tratar-se-ia no meu ponto de vista de uma complexa sistêmica - ou, ainda, de redes dinâmicas envolvendo fluxos de matéria e de energia - de caráter eco/cosmológico, porque processual e transformativo, capaz de impulsionar a vida citadina implicada nas interações dos fenômenos biofísicos e simbólicos presentes nos aglomerados humanos. Portanto, uma sistêmica desta ordem diante das agências das formas vivas e dos elementos, somadas às próprias ações humanas, tenderia a desestabilizar as paisagens construídas e entendidas como patrimônios por uma sociedade, por isso afeitas a ritmos temporais cujas vibrações em torno dos seus bens tenderiam a durar no espaço. Rocha e Eckert (2005) já mostraram que tal duração para o caso dos bens edificados no contexto brasileiro segue rítmicas outras, especialmente quando se trata de pensar acerca da agitação espaço-temporal oriunda das agências humanas, que acrescidas às forças dinâmicas da natureza nos trópicos tendem a reconfigurar as paisagens urbanas, com uma frequência distinta daquela de matriz europeia, por exemplo.

Uma instabilidade como esta nas vibrações temporais, parece-me, se afastaria de qualquer equilíbrio duradouro sobre o espaço, colocando as formas não lineares na constituição da urbe como um fenômeno difuso, mas endêmico às nossas plagas. Essa dinâmica figuraria como a expressão de um barroquismo (Morse, 1988) constitutivo das manifestações existenciais das populações brasileiras, evocando a luxúria prolífica das formas como uma tendência ao complicado no pensamento brasileiro.

As próprias maneiras de nos relacionarmos com os naturais seriam uma dimensão deste vitalismo pulsante das entidades autóctones em conjunção àquelas exógenas, mas muito bem aclimatadas ao solo sul-americano, atravessado, certamente, por contradições. Nos jogos tensos entre proximidade e distância, encantamento e temor, identificação e ojeriza, constroem-se perspectivas de relações que trazem à tona

\footnotetext{
${ }^{2}$ As migrações dos animais; as mudanças de estações; a sazonal dispersão de pólen das flores; a maturação dos frutos e o nascimento dos filhotes; as mudanças climáticas drásticas; a cíclica das marés; as catástrofes; as doenças epidêmicas, assim por diante.
} 
as maneiras ambíguas pelas quais nos relacionamos historicamente com a outridade animal (e vegetal) $)^{3}$.

De qualquer maneira a configuração de formas de associação (Latour, 2008) nos termos das conexões dos humanos com os animais não-humanos, traz consigo preceitos ético-estéticos/visões de mundo humanos variáveis em relação ao diverso de si, podendo aproximar horizontes, que se desdobram em formismos possíveis quando emergem nas cidades modernas vinculados à ordem do sensível (Sansot, 1986) e do emocional de seus habitantes, mas atrelados as experiências não urbanas ${ }^{4}$. Todavia, os animais como uma expressão da alteridade radical (Peirano, 1999; Estebanez, 2006) forçam-nos a (re)situar o nosso lugar no mundo constantemente, pelo fato de que cada vez mais nos deparamos com as suas vidas emocionais complexas, ou porque nos damos conta de nossas ações impactantes sobre o mundo que compartilhamos com eles e com os demais seres vivos.

Esta ecologia sutil, ecosófica nos termos de Guattari (1990), nos conduz a uma mirada sensível em relação aos não-humanos, porque nos leva a refletir acerca de uma eco-lógica ajustada a outros princípios que não aqueles ligados ao antropocentrismo egoísta, principalmente quando uma ecologia mental de caráter ampliado força-nos a considerá-los como "seres sencientes" (Bekoff, 2010); porque uma ecologia social nos faz repensar as associações que estabelecemos com eles; e finalmente, pelo fato de uma ecologia de matriz ecossistêmica indicar a relevância da vida planetária como um macrossistema compartilhado com os Outros, mas com enormes significações locais. A ecosofia apresenta alguns caminhos para pensarmos o nosso parentesco com o diverso de nós porque nos compromete com as diferenças.

A ideia de parentesco com os animais, por exemplo, se partimos das reflexões do etólogo cognitivo Marc Bekoff, mostra-se como uma forma ampliada de relação familiar - no interior da morada ou no oikos planetário -, especialmente no que tange a constituição de laços simbólico-práticos e afetivos com eles. Portanto, trata-se de um fenômeno interespécies que abrange dimensões existenciais diversas, que importam na

\footnotetext{
${ }^{3}$ Aqui é inevitável fazer referência ao trabalho de DaMatta (1993) quando o autor problematiza as relações contraditórias dos brasileiros em relação a natureza.

${ }^{4}$ As derivações do perspectivismo ameríndio de tipo caboclo, por exemplo, nutririam as cidades amazônicas, adentrando a urbe através de seus portos junto aos rios; as referências telúricas contribuiriam para amalgamar as relações entre campo e cidade revitalizando tradições, para o caso das cidades gaúchas; ou mesmo, quando expressões neo-religiosas evidenciam as relações com a natureza urbana presentes em metrópoles, como São Paulo, Rio de Janeiro e outras do país, apenas para citar algumas das possíveis dimensões ético-estéticas presentes no contexto brasileiro.
} 
ontogênese - que desde o processo evolutivo nos aproxima do Outro-animal, para utilizar a expressão de Yarri (2006: 22) - tendo desdobramentos ontológicos importantes no contemporâneo, que indicariam um animal turn. Ao comentar acerca das implicações do trabalho de Bekoff para o conhecimento evolutivo e etológico, bem como de sua importância quanto às reflexões sobre o parentesco e a religiosidade para os humanos em relação aos animais, a autora reconhece que para Bekoff "os animais são nossos parentes no sentido mais amplo da palavra" ${ }^{5}$. Para ele é preciso considerar as "similaridades fisiológicas, mentais e emocionais entre nós", e a partir daí "as maneiras como devemos tratá-las". Bekoff defende que "devemos entrar em seu mundo, a fim de melhor compreendê-los", o que tem implicações religiosas e éticas profundas (ibidem: 22).

O caráter parental se daria pela coexistência biosférica planetária com reverberações cosmológicas diversas, considerando tanto etnicidades distintas quanto animalidades possíveis em jogo - o perspectivismo ameríndio seria um exemplo disso -; por uma ecologia social intraespecífica porque humana, uma vez que forjam culturalmente associações mais ou menos duradouras de caráter interespecífico com os animais em consonância com agências animais. Sociações que configuram um ecossistema simbólico intersubjetivo por afinidade emocional com eles e, a partir deles, obviamente, pelo afeto mútuo - próprio aos mamíferos: digo isto, apenas porque pertencemos a tal ordem, o que não exclui tal experiência em graus diversos às demais que indicam expressões de sentimentos, de valores e de condutas. É a partir deste nível de interação que a constituição de famílias interespecíficas, envolvendo humanos e animais de companhia no contexto urbano - mas, também, dos chamados xerimbabos ${ }^{6}$ no contexto amazônico - tornam-se possíveis.

Nestes termos, coloca-se primeiramente a necessidade de discutir a importância da casa e do habitar para os humanos situados, também, em relação aos espaços verdes, pensando-os como coparticipes nas paisagens - para o caso que me interessa, urbanas. Tal cenário permite interpretar o lugar de agência dos animais de companhia, quando se avalia a importância heurística de tal "interação" de diferenças, bem como acerca das implicações fenomenológicas de compartilhar a localidade do espaço urbano com

\footnotetext{
${ }^{5}$ Tradução livre do inglês pelo autor.

${ }^{6}$ Felipe F. Vander Velden (2012) em suas reflexões sobre as relações interespecíficas entre os Karitiana e os animais por eles criados, indica a pouca atenção que os antropólogos destina(ra)m aos animais de companhia em seus estudos etnográficos. Se isto é perceptível para os estudos etnológicos, verifica-se que para o mundo urbano não é menor o desinteresse.
} 
animais silvestres - e, mesmo, em áreas de conservação na urbe -, configurando socialidades (Maffesoli, 1987; Strathern, 1992) e "coletivos" que podem ser considerados como "híbridos" (Latour, 2008), mas que trazem consigo dimensões intersubjetivas até certo ponto singulares de relação e de coexistência no atual. Ele solicita formas menos rígidas de pensamento sobre temas cujo caráter interdisciplinar aproxima tensionalmente fronteiras, ao mesmo tempo em que bifurca caminhos, apontando novos horizontes de reflexão e contribuindo para o surgimento de imagens, midiáticas, inclusive, próprias aos jogos complexos entre culturalização da natureza/naturalização da cultura no contemporâneo.

Eu mesmo me encontro inserido no universo de pessoas que optaram por ter consigo animais de companhia e que os concebem como constituintes de uma família interespecífica, pois coabito com quatro gatos - todos eles recolhidos das ruas da cidade de Belém (PA), onde vivo -, sendo assim, as pessoas que frequentam nossa morada durante as visitas e os encontros comigo, ainda que venham movidas por um tipo de interação humana, necessariamente compartilham o espaço - de alguma forma - com os felinos.

É preciso deixar claro que não pretendo tratar do cotidiano junto aos meus companheiros de moradia, ou seja, não se trata de fazer uma espécie de auto-etnografia, a fim de refletir acerca do convívio com os gatos, mas sim de partir desta experiência para pensar questões mais amplas e, eminentemente, de caráter teórico-conceitual acerca das relações entre humanos e não-humanos na urbe.

Além disso, conjugo a questão apontada acima a aspectos da etnografia que realizo junto ao Bosque Rodrigues Alves - intitulado "O Jardim Botânico da Amazônia" - na cidade de Belém (PA), situado no bairro do Marco da Légua, onde moro, à coexistência com os felinos. Tais experiências vivenciais e etnográficas são aproximadas a um amplo espectro de leituras que me levam a refletir sobre o tema das relações interespécies, pensando o coabitar humano com a alteridade animal e a conformação de uma paisagem coexistencial interespecífica urbana, a partir de seus desdobramentos simbólicos para a conformação de experiências e estilos de vida em uma metrópole amazônica, por exemplo. 
Neste caso, não se trata de pensar senão na perspectiva de uma "cidade sensível" para a qual se necessita não apenas de um método $^{7}$ - o etnográfico, no meu caso - mas, acima de tudo, de uma abordagem voltada a um estilo de pesquisa (Sansot, 1986), que permita conhecer as formas de socialidade existentes no seu corpo, cotejadas pela razão sensível (Maffesoli, 1998) que se volta ao afetivo, ao táctil e as sutilezas da memória, quando se refere às complexas interações entre humanos e não-humanos na cidade, sopesando as dinâmicas próprias à urbe.

\section{Devaneios acerca da morada humana}

A reflexão que proponho enfoca o mundo urbano contemporâneo e o universo das camadas médias, onde as ações de habitar a casa - inserida no bairro, na cidade estão associadas basicamente a processos complexos que integram as dimensões da vida social no contemporâneo, relativos tanto à psicogênese quanto à sociogênese (Elias, 1994) dos indivíduos em interação nos espaços sociais. Como esses processos formais instauram modos de vida no seio da urbe, pautados em um caráter normativo e civilizacional com forte acento intersubjetivo, apresentam influência direta sobre a psique de cada agente social. Tal extensão da experiência coletiva - proxêmica (Hall, 1977), certamente - contribuiria para a dinâmica de proximidade e de distanciamento vivida pelos indivíduos entre as esferas do privado e do público (Sennett, 1988), para a constituição do habitus, (Bourdieu, 1998; Elias, 1970, 1994; Wacquant, 2007), cuja plasticidade configuraria fronteiras simbólicas mais ou menos estáveis, de acordo com as etiquetas culturais em jogo.

Desta maneira é neste espaço protegido para o qual converge uma sutil constelação de imagens (Durand, 1989) - arquetípicas, inclusive - em torno da "caverna", do "ninho" e da "cabana" (Bachelard, 1988) e, por isso, evocadoras de uma "floração de símbolos" (Rocha, 1995) que adere a casa como edificação, que percebo a força das imagens que contribuem para a constituição da aura da morada enquanto um construto afetivo. Tem-se, assim, com as agências humanas envolvidas na conformação da paisagem doméstica do habitar a presença de um formismo cooperativo, que seria próprio à figuração emocional do lugar de pertença em consonância com a expressão do

\footnotetext{
${ }^{7}$ Sobre a pertinência de um "método etnográfico" per se, ver Peirano (2014). Sobre as tensões entre antropologia e etnografia Ingold, (2011).
} 
si habitante, bem como à abertura às relações com o mundo a partir de uma perspectiva que sopesa a sua exterioridade.

Seguindo uma inspiração fenomenológica bachelardiana, percebo o espaço de habitação do humano como lugar "privilegiado", desde uma "necessidade de estar situado" (Norberg-Schulz, 1975: 38). Logo, referido à acomodação a um nicho existencial que contribui para a emergência de sua subjetividade pautada pelos "valores da intimidade" (Bachelard, 1988: 57), o que o instiga tanto a experienciar o sentido do privado quanto à imaginação criadora a fim de assimilar as impressões do meio e, a partir daí, de agir sobre ele ao mesmo tempo em que é afetado pela relação.

A casa liga-se ao lugar e a pertença a ele por parte do humano, vinculando-se aos sentimentos que estão contidos nas "formas sensíveis da vida social" (Sansot, 1986: 53), evocadoras da experiência subjetiva associada à dimensão moral de habitar. Nestes termos, é preciso indicar que o campo antropológico há bastante tempo se debruça sobre a temática da casa humana, constituindo-se em estudo clássico na disciplina ${ }^{8}$. LéviStrauss (1987: 34) em resposta a Pierre Lamaison, afirmou: "[a] casa é antes de mais nada uma pessoa moral, detentora, inclusive, de um domínio composto por bens materiais e imateriais" $"$.

A casa como "coisa" conjugaria o material e o imaterial no corpus paisagístico, constituindo um conjunto com o seu entorno. A sua agência é justo aquela de ser o palco ativo e, ao mesmo tempo, de figurar como cenário propício às manifestações humanas sob a perspectiva de um nicho de proteção, de conforto físico e emocional: ambiência que motiva a habitar e a ser habitado por suas imagens. Para o caso brasileiro o tema da casa encontra nas reflexões de Gilberto Freyre $(1973 ; 2003)$ um de seus pensadores mais argutos, especialmente acerca da figura solene do sobrado quando discute as dimensões "sócio-históricas" caras ao sentido de habitar na América portuguesa colonial, referindo-se ao "sentimento de identificação com a casa regional". Daí que, na visão do autor:

\footnotetext{
${ }^{8}$ Para uma reflexão sobre a casa Tikópia e as relações de parentesco a ela vinculadas (afiliações, linhagens, por exemplo), refletindo-se em alianças, hierarquias e, assim, na organização social, bem como as considerações relativas às sociétés à maisons lévi-straussianas, ver Lanna (2005). O estudo clássico de Pierre Bourdieu (1999) acerca da casa kabyle é central para o tema. Sobre as diversas dimensões da habitação indígena, ver o livro organizado por Sylvia Caiuby Novaes (1983).

${ }^{9}$ Tradução livre do francês pelo autor.
} 
(...) o sobrado patriarcal teve, na nossa paisagem, alguma coisa de fortaleza sociológica e psicológica que resguardasse uma "raça" e principalmente uma "classe" - a raça autêntica ou oficialmente branca e a gente proprietária quando não de terra, de escravos, de jóias e moedas, e, em particular, a mulher e a criança aristocrática - de contatos com o mundo exterior: não só com a gente de rua, de campo e de outras casas, como com os elementos - o vento, o sol, as chuvas - os animais - indistintamente chamados de bichos - e também com as árvores e as plantas no seu estado bruto e indistintamente chamadas mato. Essa função, o sobrado patriarcal desempenhou magnificamente nos seus dias de plena fôrça. Até que chegou o período de sua desintegração, quando de suas próprias varandas, homens criados nos seus quartos, nas suas salas, nos seus pátios, dentro de suas janelas ou de suas rótulas, entre suas mucamas, seus gatos, seus papagaios, seus passarinhos de gaiola e seus cachorros, principiaram a discursar ao povo das ruas dizendo-lhes que era preciso abolir a escravidão. A abolição da escravidão seria a morte do sobrado como fortaleza sociológica e psicológica na paisagem brasileira. Exigiria uma readaptação completa do sobrado ao espaço social e geométrico e a paisagem, cultural e natural, alterada no sentido de maior prestígio da cidade e da maior socialização e democratização da vida e da natureza brasileira. (Freyre, 1973: 95-96)

As considerações de Freyre deixam claras as imagens da casa-redoma como lócus de segurança burguesa em relação ao "extra-doméstico" e ao domínio da rua (DaMatta, 1997), a tudo aquilo que escapa à domesticidade controlada - por isso, impuro; insalubre; perigoso, para evocar as imagens trazidas por Douglas (1976) - e aos domínios da interioridade coexistencial onde gentes (e gentios), mas também animais domésticos convivem com as famílias abastadas, distantes do selvático situado para além das paredes ou dos muros do edifício assobradado. O seu declínio está em paralelo às mudanças sociais vividas pela sociedade brasileira à época e a expansão da cidade enquanto traçado urbanístico que desloca os significados da casa-grande, reconfigurando as paisagens de poder (Zukin, 2000).

De qualquer forma, se partirmos de uma topologia do habitar e ponderarmos acerca da casa e do seu entorno - o quintal, o pomar, o pátio ou o jardim - a partir dos "devaneios do pertencimento" (Nogueira, 2007), percebe-se que ela toma parte na configuração das paisagens enquanto elemento coparticipe de um conjunto de signos cosmológicos conexos, como são as coisas e as cidades (Norberg-Schulz, 1975: 41). Ela vibra nas paisagens como um microcosme social (Chiva, 1987), ou mesmo, enquanto um dos axis mundi (Eliade, 1992) humano: eixo-abrigo; esteio-refúgio evocador de uma simbólica relativa à presença do lugar sagrado/de proteção no mundo vivido e praticado pelos coletivos, mesclando materialidade e imaterialidade na conformação de uma estética do habitar. 
A casa na perspectiva bachelardiana concentra em si "simultaneamente imagens dispersas e um corpo de imagens" (1988: 23-4), revelando-se um espaço existencial em que as coisas se articulam, se influenciando mutuamente enquanto formam um todo simultâneo, isto é, elas dinamizam um campo complexo, quando a imagem do todo deste campo é percebida independentemente das partes individuais (Norberg-Schulz, 1975: 41), como uma paisagem (Simmel, 2011). A sua interioridade figura como a expressão do "estado da alma" de quem a concebe como um universo íntimo onde as coisas dialogam entre si, evidenciando conexões tanto funcionais quanto àquelas relativas à estetização do mundo, próprias ao habitar. Ora, a morada permite mediante os "valores da intimidade do espaço interior" vislumbrar e praticar a localidade do espaço desde o sensível que liga o território existencial e identitário à pertença ao lugar, vividos na domesticidade cotidiana - porque relacionado "à função original do habitar" (Bachelard, 1988: 23-4).

Em verdade, a morada mostra-se como um dos lugares centrais desde onde o mundo (inter)subjetivo se revela ao humano. Sendo assim, é praticada como experiência corpórea daqueles que nela (con)vivem, envolvendo o exercício de uma série de técnicas corporais - em sua totalidade de fato social para evocar o pensamento maussiano (1974) -, implicando, por isso, uma fenomenologia dos sentidos da ordem do sensível, assim como, de uma psicologia que participa das interações sociais e, mesmo, de uma fisiologia do sono, do sexo, da alimentação e da excreção, por exemplo configurando formas socioculturais de morar que variam de acordo com o ethos, mas também com o habitus dos coletivos humanos.

A perspectiva de uma fenomenologia do habitar - ou, de uma dwelling perspective, nos termos de Ingold (2003) - situaria o humano diante do exterior a partir de suas agências em relação às coisas, que o impulsionariam a construir a sua morada. Neste caso, o exterior seria vivido como o "fora" sob a efígie do que para nós brasileiros indicaria o domínio da "rua" ${ }^{10}$, porque percebida como espaço de deambulação e, em certos momentos de desproteção, pois carregaria consigo toda a sua significação de perigo e de estranheza, de vicissitudes diante do desconhecido que paira argucioso ou

\footnotetext{
${ }^{10}$ Sobre a dinâmica relacional entre as dimensões sócio-espaciais da casa e da rua para o contexto brasileiro, ver DaMatta (1997). Os limites da casa, percebida enquanto lócus do sagrado porque espaço de preservação de si e dos oráculos às deidades, evocariam as tensões entre a interioridade (o limpo) e a exterioridade (o sujo), caras às reflexões de Mary Douglas (1976), ou mesmo, de Eliade (2005).
} 
medonho sobre os entes a partir da existência de formas plurais - materiais ou não - que circulam pelos espaços praticados ou ermos.

A dialética entre o dentro e o fora resguarda uma dinâmica que aponta para a figura ambígua da porta (Simmel, 2011). Passadouro que ao contribuir para a definição dos limites relativos à interioridade da casa, evocaria a imagem do "refúgio" (Bachelard, 1988) e mostrar-se-ia, também, como a expressão do escoamento das coisas no fluir entre o interior e o exterior, indicando condições relacionais próprias aos fenômenos em situação. Ela indicaria o fluxo das gentes e das coisas no exercício de unir "opostos entre si" no devir do espaço e do tempo, revelando dimensões sensíveis de uma expression habitante (Thibaud, 2006: 112).

A porta possui lugar especial neste processo de habitar dada a sua figuração de meio, uma vez que ela transcenderia o lugar em si, mesmo que persista nele. Ela abre-se ao espaço e possibilita a deriva pelos tantos caminhos que conduzem à/pela cidade, permitindo o ir e o vir - portanto, há uma rítmica, uma potência inerente à sua presença - daquele que se aventura pelos logradouros urbanos que se distribuem na rede citadina e seus espaços públicos. As narrativas que a porta suscita são aquelas que indicam uma "retórica deambulatória" (Sansot, 1986: 59), diante dos fluxos e das movências experimentados pelos sujeitos em seus agenciamentos possíveis na urbe. A porta define os limites e o fluir entre o privado e o público pelo ato de caminhar, diferentemente da janela, que no meu ponto de vista sugeriria muito mais o voo e, para o nosso caso, redundaria na iminência da queda.

Na metrópole amazônica, em seus diferentes lugares praticados (Certeau, 1994), a presença e a deambulação tanto de entes fantásticos quanto de animais não-humanos é recorrente e associada às dinâmicas da urbe (e seus avanços mais ou menos danosos nos espaços) em relação aos imaginários que vibram em torno das florestas e das águas. Se eles estão vinculados, até certo ponto, à exterioridade da morada, quiçá aos longes indicariam a existência de mistérios e de perigos presentes nas ruas lúgubres, nos interiores das matas densas, ou mesmo, das turvas profundezas encantadas dos rios e igarapés. Tais paisagens, fantásticas, inclusive, indicariam a condição humana diante das forças exteriores em relação ao seu refúgio, pois se por um lado a fragilizariam, por outro tenderiam a colocá-la na situação de relação e de enfrentamento do desconhecido. 
Desta forma, as sutilezas presentes nas paisagens experienciadas, além de apontarem a (i)materialidade das coisas e suas agências, revelariam certa imprecisão - a incerteza; a mestiçagem - inerente à mescla complexa de caráter biocultural presente nos "lugares praticados" (Certeau, 1994) pelo sapiens, relacionada ao seu estar no mundo e às significações que atribui ao mesmo, considerando a simbólica dos gestos que os colocam em relação com as coisas no espaço e no tempo vividos coletivamente.

Paisagens manejadas, ou aquelas praticadas porque domésticas - onde o quintal seria um signo potente -, situariam a figura da casa como um "verdadeiro cosmos" (Bachelard, 1988) que contribuiria para a percepção da diversidade das "coisas", a partir da disposição humana de habitar. Ela nutre a experiência humana de imagens-ideias acerca do morar relacionando-as à espacialidade dos lugares, percebidos como loci possíveis para a vida vivida - e compartilháveis com outros entes -, quando os devaneios do repouso e da vontade (Bachelard, 1994b, 1994a) como expressões da vida interior, mas também social, impulsionariam o espírito humano a agenciamentos coletivos a fim de criar tanto o lugar da morada - reino do conforto e da intimidade do ser no mundo - quanto a experiência de coexistir no espaço comum da cidade, considerando a heterogeneidade que lhe é intrínseca.

A casa surge, desta maneira, como uma construção técnico-cultural, um conjunto de ambiências praticáveis - coisa-artefato-objeto - que propicia toda uma fenomenologia das "formas sensíveis" (Sansot, 1986; Simmel, 1983) que anima a vida social, a partir de uma sensação de vida privada e íntima que seriam próprias ao residir em relação à esfera pública, adequada a vida urbana. Sendo assim, se o homem a constrói [a casa] é porque ele também é construído por ela. Trata-se de um vínculo movido por agências mútuas que imiscuem humanos e não-humanos numa recursividade criadora, onde a distinção entre a coisa e o ser se torna relativa, vibrando como dimensão processual de formas ônticas/ontológicas coexistindo em devir no tempo e no espaço das paisagens.

A morada contribui para que a subjetividade humana aflore, principalmente quando se considera o lugar que ocupa na sua experiência como abrigo acolhedor, traduzindo-se em paisagens de íntima familiaridade. Persiste, assim, como lugar de repouso e de existência simbólico-prática, uma vez que detém em si a fenomenologia do espaço do habitar repleta de referências e memórias, de valores e visões de mundo de quem nela habita - ou coabita com outros entes. 


\section{Do viver com animais companheiros}

As relações conviviais com os chamados "bichos de estimação" revelam-se temas caros aos modernos, ou pelo menos aos modos de vida designados como tais. Ora, as transformações das condutas humanas quanto à presença de animais no interior das habitações, logo, no seio da domesticidade familiar requer uma apreciação mais cuidadosa, principalmente quando se considera uma antropologia relativa ao estatuto do animal de companhia no corpo da referida instituição no mundo ocidental. Note-se que tal discussão escapa ao intento deste artigo, todavia a leitura de Thomas (1989) para o caso europeu, especialmente o britânico, poderia elucidar alguns aspectos para o contemporâneo $^{11}$.

De qualquer forma o que parece mudar não é necessariamente a presença conspícua dos animais tanto na urbe quanto no interior das casas, mas sim uma perspectiva de civilidade em relação a eles, que se instaura paulatinamente associada à higienização e a certo controle do vivo, especialmente quanto às doenças transmissíveis. Neste caso defrontamo-nos com novos arranjos relacionais entre humanos e animais não-humanos. Questões desta ordem permitiram níveis de proximidade e de tolerância para com os últimos, que tenderam a se estreitar diante dos avanços ligados aos conhecimentos veterinários e de profilaxia, redefinindo padrões de convívio quanto à presença de não-humanos no interior das habitações humanas.

Tal cenário se não os distancia totalmente do espaço doméstico, por outro lado, elege alguns deles como espécies caras ao contato humano - especialmente cães e gatos -, envolvendo interações da ordem da vida privada e da intimidade no seio do lar burguês (mas, não apenas dele). Note-se que as formas de interação com os animais de companhia ao sofrerem alterações ao longo do tempo, indicariam as percepções modernas acerca do seu lugar junto aos humanos, ressaltando as suas qualidades

\footnotetext{
${ }^{11}$ As ponderações de Gilberto Freyre (1979) acerca de Joujou, o gato de sua família, são interessantes para pensarmos sobre a presença dos animais de companhia no Nordeste brasileiro patriarcal. Para uma perspectiva de longa duração, ver os trabalhos esclarecedores de Katharine MacDonogh (2011) sobre os animais da corte; de Laurence Bobis (2000) e James Serpell (2000) quanto à história dos gatos; Robert Darnton (2011) sobre a dimensão cotidiana e sacrificial dos gatos na agitada França do XVIII; Robert Delort (1984) acerca da história dos animais, assim como Luc Ferry (1994). Ver também o interessante Dossiê Animais de Estimação, a fim de nuançar aspectos relativos ao seu lugar na sociedade brasileira, publicado na Revista de História do Museu Nacional, de setembro de 2010.
} 
estéticas e morais, bem como o caráter emocional das relações travadas com aqueles que apreciam suas companhias.

Os vínculos simbólico-afetivos com os animais companheiros (Haraway, 2010) revelam pontos de vista humanos bastante diversos e, por vezes, contraditórios, especialmente quando pensamos na figura ambígua do gato - despertando emoções distintas - e as representações que traz consigo no decorrer da complexa história de suas relações com os humanos, sopesando uma longa duração. O imaginário em torno da figura felina evoca um conjunto de imagens heteróclitas, ou ainda, uma simbologia acerca do animal que oscila no corpus de um amplo espectro de representações.

O que tudo indica é que uma constelação de imagens arquetípicas evocadoras de uma simbólica de caráter polissêmico orbita em torno dos felinos, contribuindo ou não para a escolha de sua presença junto às pessoas como animal companheiro. Autores como Grandin e Johnson (2010: 71) afirmam que os gatos, pelo fato de não serem considerados animais "hipersociais" como os cães, teriam um lugar na relação junto aos humanos oposto àqueles, pois segundo as autoras “[o]s cães servem às pessoas, mas as pessoas servem aos gatos". Aliás, tipo de comentário que é possível ouvir entre diversas pessoas. Outra questão importante apontada pelas autoras é a de que "os gatos ainda não foram realmente domesticados ou pelo menos nem se comparam aos cachorros" (ibidem), mantendo-se, ainda, relativamente selvagens. Em verdade, já escutei diversas vezes - e em diferentes partes do Brasil - frases que se aproximam a estas: "A relação do cachorro é com o dono enquanto que a do gato é com a casa!"; "Cachorro é mais amigo, mais sociável. Gato é mais individualista!”. Obviamente, trata-se de pontos de vista, o que não significa que concorde com eles.

O que tudo indica é que a escolha por um tipo de animal de estimação/companhia está relacionada, até certo ponto, às questões de gosto especialmente quanto ao temperamento do animal - e de classe - animais de raça, com pedigree podem representar signos de ostentação - que tendem, ainda, a instaurar diferenças entre o animal utilitário e trabalhador daquele de companhia e de luxo, por exemplo. Neste sentido, o comentário de Tânia Stolze Lima (1999: 51) quanto aos animais de apreço auxiliam a reflexão, principalmente quando a autora coloca a seguinte questão: “Quem garante que a relação com um animal de estimação seja uma constante, independentemente de ser ele um cachorro, um gato ou tartaruguinha? Quem 
garante que, para o vaqueiro, a diferença significativa entre o homem e o gado seja a mesma que existe para com o cavalo?" 12

De qualquer maneira o que precisa ficar claro é o fato de que nós, enquanto humanos, não estamos necessariamente sós na casa e/ou em seu entorno. Ao afirmar isto não estou considerando apenas a domesticidade que inclui os animais de companhia - gatos e cães, por excelência -, mas incluo o domesticus presente nas formas vivas conhecidas como espécies sinantrópicas ${ }^{13}$ - desde invertebrados a mamíferos e aves, inclusive, comensais, porque muitas vezes são afeitas ao consumo de resíduos humanos -, e que longe de representarem apenas o infestans exercem a sinantropia como forma de habitar junto ou próximo ao humano numa paisagem coexistencial e, desta forma, interespecífica, considerando-se uma ecossistêmica urbana vivida cotidianamente.

Se tais paisagens emergem nas experiências do sapiens com outras criaturas em contextos diversos, tenho interesse em discutir as relações inerentes à dinâmica da ecologia urbana em que as casas e os quintais, os jardins públicos e os parques, os bosques e as praças edificados, ocupam lugar de destaque no espaço citadino. A modelagem dos cenários-ambiências pelo humano ocorre a partir de seus agenciamentos nas paisagens em consonância com as próprias agências das paisagens - desde os seus ritmos, climas, cismas - constituindo as suas auras. A plástica adaptativa inerente à vida nas cidades é tão verdadeira para o humano como expressão de sua vida simbólica, quanto aos animais e as plantas em seus processos de interação com as coisas que o homem constrói para o bem ou para o mal no mundo urbano.

O conviver e, mais do que isto, o coabitar com animais indicaria, contrastivamente, certas dimensões da nossa própria humanidade. Todavia, não necessariamente a nossa humanidade per se entendida como oposição antropocêntrica que inferioriza a animalidade alheia, pois se aproximarmos os pensamentos de Bekoff (2010) ao de Viveiros de Castro (2002), ou àquele de Ingold (2011), fica claro que as nossas diferenças são mais de grau do que de tipo. Questões desta ordem indicariam a existência humana enquanto forma de ser/estar-no-mundo em relação com entes diversos, a partir de nossa condição ambígua de “animais humanos” (Durand, 1989).

\footnotetext{
${ }^{12}$ As questões levantadas por Stolze Lima (1999) podem ser aproximadas às considerações de Banducci Júnior (1999), quando o autor reflete sobre as relações dos peões de gado com a fauna pantaneira.

${ }^{13}$ Sobre o tema da fauna urbana, ver Piedade (2013).
} 
Se partirmos do derivar adaptativo processual desde as formas ontogenéticas às expressões ontológicas, que confluem no caráter expressivo do sapiens enquanto ser-aí (Heidegger, 2012), precisamos considerar a sua coexistência com as formas do vivo sem jamais prescindirmos das coligações que os vinculam aos entes não-humanos (por certo, também, ontogenética e ontologicamente) a partir do sentido de pertença ao mundo, ora entendido como o profundo vínculo cosmológico - que poderia ser ao macrossistema autopoiético/mental de Gaia. Tal afirmação é, no meu ponto de vista, uma conexão entre os pensamentos de Bateson (1990), de Maturana e Varela (1997) àqueles de Lovelock (2009) - desdobrando-se na própria constituição simbólico-prática do sapiens como ser autônomo, ou simplesmente como símio imerso na vida simbólica.

Somos humanos porque os não-humanos e os sobre-humanos existem como ontologias diversas (e em trânsito), as quais nos colocam e nos forçam a ocupar certo lugar (ético-moral, inclusive), quiçá uma posição diante dos Outros que nos revelariam as formas plurais da mesmidade humana (Ricoeur, 1994), por si só um universo estrutural complexo envolvendo tensões e possibilidades de arranjos simbólicos desde as suas diferenças. Daí que a presença das alteridades humanas e não-humanas em relação revelariam, contraditoriamente, tanto as formas de colonialismos e de opressões dos humanos entre si, como dos humanos sobre não-humanos, ou se quisermos, daquilo que entendemos por "natureza".

A questão da chamada subalternidade (Spivak, 1988) coloca em pauta as assimetrias existentes entre os humanos, indicando, ainda, a submissão da natureza nãohumana à cultura hegemônica humana - de matriz ocidental e judaico-cristã, principalmente - que cada vez mais precisa se deparar com formas culturais nãohumanas que deslocam o lugar tácito do humano, como sendo capaz tanto de produzir cultura quanto de possuir consciência de si; de engendrar agências e de possuir emoções complexas. Além do mais, uma visão que considere a diversidade cultural precisa lidar com as distintas concepções de natureza, de animalidade/vegetalidade e de humanidade, como sendo aspectos presentes no mundo vivido/pensado das sociedades humanas a partir de percepções distintas e evocadoras de cosmologias não centradas no monoteísmo judaico-cristão e/ou no método científico - sopesando uma ortodoxia reducionista inerente a certo fazer científico -, como formas de compreender e de viver o mundo que concebem relações totalmente diversas com não-humanos. 
No que tange à construção de nichos de coabitação na urbe - aqui, me apoio nas considerações de Fuentes (2010) quando o autor discute os niches constructions entre humanos e não-humanos - reflito acerca do tema a partir da casa, entendida como "o lugar central da existência humana" (Norberg-Schulz, 1975: 39) com o animal. Aqui o com expressa o sentido de companhia interespécies, ou ainda ao estar com que Haraway (2010) aponta para a relação humano-animal doméstico e que, no meu ponto de vista iria ao encontro da noção de estar-junto em relação de Maffesoli (1987), referida ao afetual, com a diferença que aqui se trataria de uma interação interespecífica e não intraespecífica, como aparece na abordagem do autor, indicando formas de socialidades ${ }^{14}$ humanas.

A socialidade em Michel Maffesoli, parece-me, pode encontrar certas proximidades nas reflexões de Marilyn Strathern $(1992,1999)$ sobre o tema, todavia é preciso deixar claro que não se trata da mesma coisa, e nem mesmo, para a referida autora tratar-se-ia de considerar demasiadamente um caráter emocional da socialidade, como aparece com evidência no primeiro. Isto não quer dizer que para Strathern a intersubjetividade não esteja presente na constituição das relações sociais, de suas conexões, pois é preciso refletir sobre os regramentos e os laços simbólico-práticos vinculados à coesão social em torno do qual orbitariam moralidades próprias, que contribuiriam, para o caso deste estudo, na emergência de relações interespecíficas.

Acredito que, respeitando as diferenças de matriz de pensamento, ambas as abordagens em torno da socialidade - Maffesoli francamente formista (com evidente influência simmeliana) enquanto Strathern declaradamente formalista (1999) - podem contribuir para o entendimento dos fenômenos relacionados às interações humanimais enquanto expressões formais presentes no mundo urbano amazônico, por exemplo, mas não somente nele. Um meio termo entre a plasticidade formal no primeiro autor e o caráter mais formalista e duradouro na segunda autora, pode auxiliar-nos quanto a questão da duração, ou ainda, da permanência e dos sentidos dos elos construídos entre humanos e não-humanos no espaço e no tempo sociais. De qualquer maneira, a socialidade ${ }^{15}$ é um "vetor de relações" (Maffesoli, 1989, 1994) extremamente complexo

\footnotetext{
${ }^{14}$ A noção de socialidade é extensível aos primatas não-humanos como expressão das relações sociais envolvendo um amplo espectro de interações, mais ou menos hierarquizadas, mais ou menos agonísticas. Para tanto, ver a dissertação de mestrado de Decanini (2006) sobre saguis-do-cerrado (Callithrix peniciliatta).

${ }^{15}$ Para Eduardo Viveiros de Castro (2002: 313-14): “(...) A antropologia contemporânea tende a recusar concepções essencialistas ou teleológicas da sociedade como agência transcendente aos indivíduos. À sociedade como ordem (instintiva ou institucional) dotada de uma objetividade de coisa, preferem-se
} 
no mundo contemporâneo, configurando híbridos nas paisagens (Silveira, 2009b), ou mesmo, paisagens híbridas ${ }^{16}$.

Para finalizar este tópico devo ressaltar que estou longe de negar dimensões do "trajeto antropológico" (Durand, 1989) que seriam próprias às experiências civilizacionais forjadas no Ocidente, e toda a importância relativa à sua simbólica, bem como das questões complexas envolvendo os entrelaçamentos das ciências com as tecnologias, como feições de certa singularidade humana no mundo. No entanto é preciso repensá-las a partir das formas de socialidade humanimal contemporâneas, especialmente diante da emergência científica, inclusive, que constata a existência dos animais não-humanos como "seres sencientes e sapientes" (Bekoff, 2010: 13).

Aliás, questão esta que diversos coletivos humanos em diferentes contextos sempre estiveram conscientes, à sua maneira, de perspectivá-los. Sendo assim, uma ciência epistemologicamente renovada e aberta ao cruzamento de campos disciplinares, sem com isso perder o horizonte disciplinar, e ao mesmo tempo permeável ao diálogo com distintas expressões formais e gnósticas de conceber as relações com os entes nãohumanos, seria capaz de indicar as bifurcações de tais temas no contemporâneo por caminhos díspares, mas não excludentes àquelas epistemologias xamânicas - que, para o caso latino-americano ressoam às perspectivas ameríndias, caboclas e afro-americanas (ou mesmo, influenciadas por elas) - a fim de compreendermos melhor as nossas relações com eles, principalmente, para o caso das paisagens coexistenciais urbanas no Brasil.

\section{Interacionismo simbólico humanimal a partir dos vínculos interespécies}

A simbólica relativa às associações interespecíficas de caráter ecológico entre humanos e felinos, por exemplo, indica certo mutualismo que se não é da ordem do fisiológico stricto sensu - como poderia suscitar certa ecologia do vivo, uma vez que não se trataria de relações simbióticas obrigatórias, pois não há fusão de corpos entre

noções como socialidade, que exprimiriam melhor o processo intersubjetivamente constituído da vida social". Haveria para este autor um "abandono das concepções estruturais da sociedade em favor de pragmáticas da agência social capazes de 'promover uma recuperação do sujeito sem cair no subjetivismo' (Giddens, 1979: 44)”. A abordagem de Ingold (2011) sobre o tema é relevante e aparece implicitamente em minhas considerações ao longo do texto, especialmente em torno das adequações/dos entrelaçamentos entre humanos e não-humanos.

${ }^{16}$ Sobre híbridos ver Latour (1994). No entanto, aqui inspiro-me no site do Grupo de Pesquisas Paisagens Híbridas, da UFRJ. Ver http://www.paisagenshibridas.com.br 
eles ${ }^{17}$-, por certo, se desdobra na mútua agência que assume a forma associativa simbólico-prática envolvendo o compartilhamento do nicho espacial com significativo acento emocional $^{18}$, porque ligado à coexistência afetiva. Aqui, o que está em jogo é um tipo de "interacionismo simbólico" de caráter diverso daquele que comumente estudamos como cientistas sociais ${ }^{19}$, implicando relações entre os sapiens, portanto da ordem do intraespecífico pelo fato de dizerem respeito às interações de humanos entre si em determinados contextos sociais, envolvendo estratégias de interação em público, ou mesmo, na ordem do privado.

As dinâmicas formais de associação entre humanos e felinos - para tomar como exemplo experiências/observações pessoais - em condições de coexistência no lugar do humano (a casa; o apartamento, enfim, a moradia), desencadeiam relações complexas vinculadas a uma teia difusa de significações ecosóficas, para evocar o pensamento geertziano (1989) e aproximá-lo de Guattari (1992), as quais possibilitam a reflexão acerca dos sentidos do convívio interespécies no mundo urbano contemporâneo, capazes de indicar caminhos para a vivência de um "novo habitat" próprio à "restauração" de uma "cidade subjetiva" (Guattari, 1992: 175-177).

$\mathrm{Ou}$ ainda, tais relações apontariam às vicissitudes próprias às experiências intersubjetivas de viver juntos sob a influência simbólica humana, que definem códigos e maneiras de comunicação decifráveis pelos animais, e vice-versa, já que a "subjetividade entrou no reino de um nomadismo generalizado" nas cidades, enquanto

\footnotetext{
${ }^{17}$ A noção de simbiose como coexistência fusional de seres distintos que geraram a partir de processos evolutivos uma "nova forma de vida" (Margulys, Schwartz e Dolan, 1999: 213) e que, portanto, necessitam uns dos outros para habitar e viver em determinadas condições ecológicas, como seria o caso das diversas formas de líquens resultantes de associações interespecíficas entre algas e fungos, não se aplica aqui. Por outro lado, evoco a imagem da Biofilia (Grinde e Patil, 2009), que longe de ser um mero determinismo sociobiológico, representaria a forma de interação entre seres diversos, indicando a importância biopsicosocial para os humanos de se relacionarem com não-humanos: as formas vivas animais e vegetais em interação com a cíclica dos elementos abióticos, que constituiriam em seu conjunto aquilo que entendemos por natureza, obviamente sob diferentes formas, interações e cosmologias, figurando, assim, enquanto parcela significativa da manifestação da vida planetária, ou ainda, do macrossistema simbiótico ao qual James Lovelock (2009) chamou Gaia, como uma referência direta ao mito.

${ }^{18}$ As questões apontadas por Mauss (1974) acerca do Fato Social Total auxiliam a compreensão da complexidade cultural que é própria ao fenômeno analisado, especialmente quando pensamos as conexões ainda por serem mais bem compreendidas entre a Biologia, a Psicologia e a Sociologia, conformadoras do humano como um complexo fato biopsicossocial de relevância antropológica - para tanto ver Morin (1976).

${ }^{19}$ Para esta reflexão me apoio nas pesquisas de Alger e Alger (1997; 1999). Obviamente, o que estou propondo é um diálogo com Goffman (1966; 1969; 2007; 2011); Hall (1977), considerando, ainda, os comentários de Joseph (2000) sobre o trabalho de Goffman, entre outros.
} 
máquinas imensas "produtoras de subjetividade individual e coletiva" (ibidem: 169172), possuidoras de espaços de celebração (Maffesoli, 1994) como seriam determinadas áreas verdes que conjugam sociabilidades e conservação da biodiversidade urbana.

Todavia, tais agências comunicacionais são sempre mediadas pela interpretação humana acerca do que representaria a mensagem sígnica e/ou a performance animal (felina, para o caso), a fim de situá-las num campo de entendimento sobre o devir animal (felino) no mundo humano, que estou chamando aqui de interacionismo simbólico humanimal ${ }^{20}$, pelo fato de que configura uma formismo interespecífico de caráter cultural a partir da existência de um coletivo interespécies.

O gato participa na interação como criatura detentora de agências por tratar-se de uma entidade autopoiética autônoma (Maturana e Varela, 1997), que escolhe como se relacionar com o outro-humano. Ele ocupa e instaura um lugar específico na simbólica humana ligada ao experienciar o mundo com o diverso de si. Tal aspecto se daria tanto pela sua dimensão de coisa vivente que participa moralmente das dinâmicas de socialidade (Strathern, 1992) com o "animal humano" (Durand, 1989), quanto pela figura arquetípica/mítica - e, portanto, sensível - que representa, por exemplo, sendo o seu comportamento visto, em alguns casos, como o de uma verdadeira "deidade" evocando a imagem da deusa egípcia Bastet - passando pela figuração diabólica que vincula o gato preto à bruxaria, a partir de visões e de crenças de caráter popular.

Nestes termos, ele tende a (re)atualizar tais imagens na ordem dos rituais cotidianos, próprios às formas sensíveis da vida vivida que ocorrem na domesticidade da casa, vibrando como potência do imaginário (Durand, 1989); ou ainda, vincula-se a um mundus imaginalis (Corbin, 1972) que veicula certas imagens sensíveis, mas contraditórias - os gatos paparicados das madames em contraposição aos gatos de rua vagabundeando pelos becos e telhados - as quais vibram e duram no tempo prenhes de sentidos que aderem aos bichanos ${ }^{21}$.

\footnotetext{
${ }^{20}$ Aqui a referência ao título da revista Humanimalia: A journal of human/animal interface studies é evidente.

${ }^{21}$ Há, ainda, a sua "função" saneadora e prestadora de serviços diante da eliminação de determinadas "pragas" - principalmente quanto ao controle de roedores comensais que atormentam o cotidiano doméstico dos lares - que, no entanto, se conflita àquela de vetor de doenças transmissíveis aos humanos, tais como a hidrofobia, a toxoplasmose, entre outras.
} 
Vinciane Despret (2008) em artigo inspirador aponta caminhos interessantes para a compreensão dos jogos de leituras/interpretações recíprocas entre humanos e não humanos produtores de linguagens próprias à interação - com a configuração de uma espécie de dialeto adequado a ela, como seria o caso das palavras, dos sons e dos sinais que utilizo (e invento) para me comunicar com os felinos que convivo como xerimbabos/parentes, os quais respondem com gestos (cabeçadas, toques com as patas, lambidas, entre outros), miados e sons que produzem para manifestar vontades, emoções em relação a mim.

Além do caráter intersubjetivo da relação há intencionalidades na associação, pois da mesma forma que podem vocalizar e me estimular a uma resposta a partir de suas agências, também indicam algum tipo de interação perceptível desde a minha leitura acerca do que experienciam no âmbito da morada. Sendo assim, entendo que se comunicam de diversas formas comigo porque sabem ler minhas ações/emoções/gestos em relação às suas presenças - o que Despret (2008: 134), a partir dos estudos de Jocelyne Porcher para o caso dos criadores de animais (vacas e porcos, principalmente) denomina de perspectivism of the breeders ${ }^{22}$ - na medida em que me esforço para comunicar-me com eles, o que pode "borrar as fronteiras entre humanos e nãohumanos", principalmente devido ao fato de que desde as fronteiras, nos aproximamos mediante formas comunicacionais próprias à coexistência interespecífica na ambiência que partilhamos. Obviamente que outra família interespecífica forjará interações diversas porque envolvem entes distintos em relação, e isto é signo de produção de diferenças na construção simbólica das interações humanos/não-humanos na urbe.

Tais questões indicam formas de comunicação elaboradas e, por isso, de caráter simbólico por parte dos animais porque vividas na relação com o humano, que a meu ver extrapolariam o nível mais basilar do signo: a consciência de si humana está em paralelo às formas de manifestação de percepção animal, engendrando, assim, formas plurais porque conexas de coexistência na casa. Não se trataria de uma conversa no sentido de fala articulada com palavras - ainda que eu fale com eles -, por que não é o

\footnotetext{
${ }^{22}$ Vinciane Despret (2008: 134) afirma que quando "alguém fornece palavras como escrevendo intenções. Esta prática inscreve o animal no mundo da "fala' o que contribui para 'preenchê-lo", ou seja, isto contribui "para atenuar as fronteiras entre humanos e animais. Na sua visão ao fazer-se falar e ao fazer-se perguntar coloca-se no lugar do outro, de modo a "preencher com". Não se interpreta, se experimenta. Isso não surge a partir do que é normalmente referido à empatia, mas ao invés disso, a uma forma nãoimediata de conhecimento, o que permite a construção da perspectiva daqueles que se conhece (...) Não se substitui o ponto de vista por outro, pelo contrário, tudo é feito pela adição de pontos de vista. Criadores são perspectivistas: cada perspectiva é composta da tradução das intenções". Tradução livre do inglês pelo autor.
} 
caso, mas sim de possibilidades de entendimento - parcial, provisório, repleto de elipses e desvãos, para evocar Geertz (1989) - aliás, como qualquer tipo de comunicação. Tratase aqui de considerar o processo mental enquanto uma construção humanimal. Neste caso, os gatos participariam na interação desde uma "perspectiva felina" (White, 2013: 93-94) indicando as suas agências - subjetivas; sensoriais; sencientes - de maneira a "descentrar" a minha agência humana como tal e, assim, de re-situar a experiência antropocêntrica $^{23}$.

A fala não garante o entendimento do sentido que vem à tona no encontro das diferenças, na sua dimensão pública, da mesma forma que miados não comunicam necessariamente uma felinidade ao mundo humano. No entanto, definem expressões interespécies ligadas ao relacionar-se com o diverso de si, como uma via outra de caráter sensível, alternativa, e que nos conduz aos possíveis de uma comunicação no mundo por caminhos enviesados, que escapam ao que seria próprio ao inter-humano como espécie distinta. A linguagem, aqui, reflete outra ecologia admissível que não aquela propriamente humana, sem jamais prescindir dela.

As pesquisas da psicóloga Irene Pepperberg junto aos papagaios cinza do Gabão são ilustrativas no que se refere às produções de significados compartilhados por humanos e não-humanos nas interações, e que fazem sentido no contexto no qual ocorrem como fenômenos interespecíficos de comunicação. Conforme Vinciane Despret (2008: 125):

Quando Alex, o primeiro papagaio cinza do Gabão a colaborar na pesquisa de Pepperberg, inadvertidamente produziu um som significante novo, os pesquisadores agiram como se este som fosse intencional e responderam a este novo ato de linguagem, como se Alex quisesse pedir ou comentar algo intencionalmente. O efeito da incompreensão, do "e se", é que um som produzido acidentalmente pode, assim, tornar-se uma palavra que significa algo para o papagaio porque significou algo para o pesquisador. Significados são construídos em um movimento constante de sintonia, fazendo-os emergir. Esta estratégia, sintoniza significados, ajustando-os, e inscreve-se mais amplamente no trabalho de Pepperberg em um aparato que redistribui o controle ${ }^{24}$.

\footnotetext{
${ }^{23}$ A discussão que Kara White (2013) expõe sobre a "perspectiva felina" é estimulante, porém, no meu ponto de vista a autora não avança muito no tema proposto.

${ }^{24}$ Tradução livre do autor.
} 
Nestes termos as significações humanas afetariam o existir felino e vice-versa. Ambos responderiam às solicitações destinadas um ao outro em termos contextuais, produzindo formas simbólicas a partir do existir humano com a alteridade animal no lugar de convívio cotidiano. Tais pontos de vista, por assim dizer, definiriam jogos fenômenos que para Huizinga (2000: 37) estão na base da simbolização - pois precedem a cultura e, em relação aos quais poderíamos dizer, inclusive, que seriam expressões formais não-humanas de associação, uma vez que são inerentes à vida animal.

Ora, se pensamos nos jogos e nas suas dimensões lúdicas evocamos as imagens das regras, das disputas e dos conflitos, das formas de respeito e de temor, de experiências conjuntas de sentimentos e, por certo, de expressões recíprocas de compartilhamento de afeto e de amor. Experiências deste nível deslocariam por intermédio da subjetividade o instintual e o sígnico, vistos como meras respostas a estímulos, instaurando, assim, formas comunicacionais complexas da ordem de uma simbólica interespecífica com forte caráter intersubjetivo.

Isto nos leva a pensar nas significações passíveis de serem decodificadas pelo vivo, pois desde o signo decifrado por um protista diante de estímulos luminosos, passando pela produção de artefatos por chimpanzés, ou a resposta felina a um código que interpreta como sendo um apelo de seu dono solicitando a sua presença junto a ele, indicariam a sua autonomia como entes sensíveis. No entanto, para o caso que me interessa tais dimensões emergem das especificidades simbólicas dos humanos com os não-humanos relacionados entre si, quando permutam significados no coexistir interespecífico próprio ao interior da casa, especialmente a partir de uma ecologia das significações do habitar com a diferença específica.

Quando afirmo isto não estou necessariamente comungando com as reflexões de Alger e Alger (1997; 1999) acerca do interacionismo simbólico felino, e nem tomo o interacionismo simbólico goffmaniano - referido aos humanos - de maneira a igualá-lo em termos de complexidade àquele interespecífico apontado pelos primeiros autores entre humanos e felinos, simplesmente por serem distintos e engendrarem complexidades diversas. A minha leitura sobre o trabalho dos autores junto aos felinos albergados, é a de que eles estão muito mais preocupados com a dimensão comunicacional inter-felina no âmbito dos espaços humanos, portanto, altamente culturalizados, do que necessariamente na produção de um interacionismo humanimal que se volta para as complexas relações entre humanos e gatos como dimensões 
simbólicas da coexistência interespécies, ainda que por vezes pareçam indicar algo parecido.

Para mim trata-se muito mais de uma simbólica que parte do devir humano com o Outro-animal desde a construção comum de entendimentos e de deciframentos de códigos partilhados mediante agências convergentes. Tais códigos emergem do existir humano que culturaliza a natureza felina - quiçá a animal - que responde consciente e subjetivamente aos apelos da simbólica humana, na medida em que, para além (mas sem negá-la) de uma espécie de cultura de consumo pet, se configurariam formas associativas altamente elaboradas através de interações cotidianas de compartilhar sentidos próprios ao coexistir - tomando a interioridade da casa como espacialidade do lugar (Tuan, 1983) praticado e vivido (Certeau, 1994) - e, desta forma, como produção de cultura forjada na interespeciedade porque intersticial às fronteiras que unem/separam humanos e animais.

A existência dos felinos domésticos ao nos colocar a condição humana como relacional em termos interespecíficos, mais que um fato prosaico, parece indicar-nos que é preciso (re)considerar a sua participação - aqui os gatos são figura de retórica e, metonimicamente implicam todos os animais, especialmente os chamados de estimação - no exercício constante de construirmo-nos como humanos, o que nos conduz a repensarmos a humanidade nas suas ambiguidades bioculturais e, por assim dizer, ontológicas/genéticas, associando o devir do ser - as suas características na existência mundano-espiritual - ao phûlon, que nos une por caminhos evolutivos aos grupos que constituem os entes vivos.

Questões desta ordem conduzem a trocas com o diverso de si a partir da experiência de convívio com a "alteridade radical”, que ainda que seja silvestre, parcial ou totalmente domesticada, sempre guardará um nível de autonomia, onde reside a possibilidade de abertura dialógica desde as nossas diferenças, as quais seriam configuradoras de paisagens coexistenciais no contexto urbano. Dito isto, os gatos seguem dormindo o sono dos deuses na noite equatorial amazônica. 


\section{Referências}

ALGER, Janete M.; ALGER, Steven. Beyond Mead: symbolic interaction between humans and felines. Society and Animals, 5(1): 65-81, 1997.

ALGER, Janete M.; ALGER, Steven. Cat culture, human culture: an ethnographic study of a cat shelter. Society and Animals, 7(3): 199-218, 1999.

BACHELARD, Gaston. A Poética do Espaço. São Paulo: Martins Fontes, 1988.

BACHELARD, Gaston. A terra e os devaneios da vontade. São Paulo: Martins Fontes, 1994 a.

BACHELARD, Gaston. A terra e os devaneios do repouso. São Paulo: Martins Fontes, 1994b.

BANDUCCI JÚNIOR, Álvaro. Os peões de gado e a representação dos animais no Pantanal de Nhecolândia. Cadernos de campo, USP, 8: 107-123, 1999.

BATESON, Gregory. Os homens são como planta. A metáfora e o universo do processo mental. In: THOMPSON, W. I. (Org.). Gaia: uma teoria do conhecimento. São Paulo: Gaia, 1990, pp. 35-44.

BEKOFF, Marc. A vida emocional dos animais. Alegria, tristeza e empatia nos animais. Um estudo científico capaz de transformar a maneira como os vemos e os tratamos. São Paulo: Cultrix, 2010.

BOBIS, Laurence. Une histoire du chat. De l'Antiquité à nos jours. Fayard, 2000.

BOURDIEU, Pierre. O Poder Simbólico. Rio de Janeiro: Bertrand Brasil, 1998.

BOURDIEU, Pierre. A casa kabyle ou o mundo às avessas. Cadernos de campo, USP, 8: $147-$ 159, 1999.

BURKE, Peter. La historia social y cultural de la casa. Historia Crítica, 39: 11-19, 2009.

CAIUBY NOVAES, Sylvia (Org.). Habitações Indígenas. São Paulo: Nobel/EdUSP, 1983.

CALÁVIA SAEZ, Oscar. Família animal. Revista de História da Biblioteca Nacional, 60: 2931, 2010.

CARRITHERS, Michael; BRACKEN, Louise J.; EMERY, Steven. Can a Species Be a Person? A Trope and Its Entanglements in the Anthropocene Era. Current Anthropology, 5(52): 661685, 2011.

CHARLES, Nickie; DAVIES, Charlotte A. My Family and Other Animals: Pets as Kin. Sociological Research Online, 13(5)4, 2008. http://www.socresonline.org.uk/13/5/4.html

CHIVA, Isac. La maison : le noyau du fruit, l'arbre, l'avenir, Terrain, 9: 5-9, 1987.

CORBIN, Henri. Mundus imaginalis or the imaginary and the imaginal. Zürich, 1972, 13pp. www.bahaistudies.net/asma/mundus_imaginalis.pdf

DAMATTA, Roberto. Em torno da representação de natureza no Brasil: pensamentos, fantasias e divagações. In: Conta de Mentiroso. Sete ensaios de antropologia brasileira. Rio de Janeiro: Rocco, 1993, pp. 91-123.

DAMATTA, Roberto. A Casa e a Rua - Espaço, cidadania, mulher e morte no Brasil. Rio de Janeiro: Rocco, 1997.

DARNTON, Robert. O grande massacre de gatos e outros episódios na história cultural francesa. São Paulo: Graal, 2011.

DECANINI, Daniel P. Socialidade em Sagüis do Cerrado (Callithrix penicillata): Estratégias Comportamentais nas Relações Intra e Intergrupo. Programa de Pós- Graduação em Ecologia, UnB, 2006.

DELORT, Robert. Les animaux ont une histoire. Éditions du Seuil, 411-447, 1984.

DESCOLA, Phillippe. Estrutura ou sentimento: a relação com o animal na Amazônia. MANA, 4(1): 23-45, 1988.

DESPRET, Vinciane. The becomings of subjectivity in animal worlds. Subjectivity, 23: 123139, 2008.

Dossiê Animais de Estimação. In: Revista de História do Museu Nacional, nº 60, 2010.

DOUGLAS, Mary. Pureza e perigo. São Paulo: Perspectiva, 1976.

DUARTE, Luís F. D. Três ensaios sobre pessoa e modernidade. Boletim do Museu Nacional, 41:1-69, 1983.

DURAND, Gilbert. As Estruturas Antropológicas do Imaginário. Lisboa: Presença, 1989.

ELIADE, Mircea. O mito do eterno retorno. São Paulo: Mercuryo, 1994. 
ELIADE, Mircea. Le sacré et le profane. Paris: Gallimard, 2005.

ELIAS, Norbert. Introdução à sociologia. Lisboa: Edições 70, 1970.

ELIAS, Norbert. A sociedade dos indivíduos. Rio de Janeiro: Jorge Zahar Ed., 1994.

ERIKSON, Phillippe. Animais demais... os xerimbabos no espaço doméstico matis (Amazonas). Anuário Antropológico, UnB, pp.15-32, 2011 II/2012.

FAVRET-SAADA, Jeanne. Ser Afetado. Cadernos de Campo, São Paulo, USP, (13)13:155-161, 2005.

FERRY, Luc. A Nova Ordem Ecológica: A Árvore, O Animal, O Homem. São Paulo: Ensaio, 1994.

FOUCAULT, Michel. Microfísica do poder. Rio de Janeiro: Graal, 1982.

FREYRE, Gilberto. Sugestões para o estudo histórico-social do Sobrado no Rio Grande do Sul. Problemas Brasileiros de Antropologia. Rio de Janeiro/Brasília: Livraria José Olympio Editora/Instituto Nacional do Livro, $4^{\mathrm{a}}$ ed., 1973, pp. 84-98.

FREYRE, Gilberto. Pessoas, coisas \& animais. São Paulo: MPM Propaganda, 1979.

FREYRE, GilbertoCasa-grande \& senzala: formação da família brasileira sob o regime da economia patriarcal. São Paulo: Global, 48ª ed., 2003.

GARCÍA-CANCLINI, Néstor. Estudos sobre cultura: uma alternativa latino-americana aos cultural studies. Revista FAMECOS, Porto Alegre, 30: 7-15, 2006.

GEERTZ, Clifford. A Interpretação das Culturas. Rio de Janeiro: LTC, 1989.

GOFFMAN. Erving. Behavior in publics place. Notes on the social organization of gatherings. The Free Press: New York, 1966.

GOFFMAN. Erving. Strategic interaction. University of Pennsylvania Press: Philadelphia, 1969.

GOFFMAN. Erving. A representação do eu na vida cotidiana. Petrópolis: Vozes, 2007.

GOFFMAN. Erving. Ritual de interação. Ensaios sobre o comportamento face a face. Petrópolis: Vozes, 2011.

GRANDIN, Temple; JOHNSON, Catherine. O bem-estar dos animais. Proposta de uma vida melhor para todos os bichos. Rio de Janeiro: Rocco, 2010.

GRINDE, Born. and PATIL, Grete G. Biophilia: does visual contact with Nature impacto $\mathrm{n}$ Elath and well-being? Int. J. Res. Public Health , 6: 2332-2343, 2009.

GUATTARI, Félix. As três ecologias. Campinas: Papirus, 1990.

GUATTARI, Félix. Caosmose. Um novo paradigma estético. Rio de Janeiro: Editora 34, 1992.

HALL, Edward T. A dimensão oculta. Rio de Janeiro: Francisco Alves, 1977.

HARAWAY, Donna. Manifeste des espèces de compagnie. Chiens, humains et autres partenaires. Éditions de l'éclat, 2010.

HEIDEGGER, Martin. Ser e Tempo. $7^{\text {a }}$ ed. Petrópolis: Vozes; Bragança Paulista: Ed. Universitária São Francisco, 2012.

HOROWITZ, Alexandra C.; BEKOFF, Marc. Naturalizing anthropomorphism: behavioral prompts to our humanizing of animals. Anthrozoös, 20(1): 23-35, 2007.

HUIZINGA, Johan. Homo ludens. São Paulo: Perspectiva, 2000.

INGOLD, Tim. The Perception of the environement. Essays livelihood, dwelling and skill. Londres: Routledge, 2000.

Routledge, 2011.

Being alive: essays on movement, knowledge and description. New York:

JOSEPH, Isaac. Erving Goffman e a microssociologia. Rio de Janeiro: Editora FGV, 2000.

KEELEY, Brian L. Anthropomorphism, primatomorphism, mammalomorphism: understanding cross-species comparisons. Biology and Philosophy, 19: 521-540, 2004.

LAMAISON, Pierre; LÉVI-STRAUSS, Claude. La notion de maison, Terrain, 9: 34-39, 1987.

LANNA, Marcos. A noção de 'casa': considerações a partir de R. Firth e dos Tikopia. Revista ANTHROPOLÓGICAS, 16(1): 53-86, 2005.

LATOUR, Bruno. Jamais fomos modernos. Rio de Janeiro: Ed. 34, 1994.

LATOUR, Bruno. Reensamblar lo social. Uma introducción a la teoria del actor-red. Buenos Aires: Manantial, 2008. 
LESTEL, Dominique. Portrait de l'animal comme sujet. Revue de synthèse, 4(1): 139-164, 1999.

LIMA, Tânia S. Para uma teoria etnográfica da distinção natureza e cultura na cosmologia Juruna. RBCS, 40(14): 43-52, 1999.

LOVELOCK, James. The vanishing face of Gaia. A Final Warning. New York: Basic Books, 2009.

MAcDONOGH, Katherine. Histoire des animaux de cour. Paris: Petit Bibliothèque Payot, 2011.

MAFFESOLI, Michel. O Tempo das tribos. O declínio do individualismo nas sociedades de massa. Rio de Janeiro: Forense Universitária, 1987.

MAFFESOLI, Michel. O poder dos espaços de celebração. Rev. TB, Rio de Janeiro, 116:59-70, 1994.

MAFFESOLI, Michel. Elogio da razão sensível. Petrópolis: Vozes, 1998.

MALAMUD, Randy. How people and animals coexist. http:chronicle.com Section: The Chronicle Review Volume 49, Issue 20, Page B7, 2003. http://english.gsu.edu/pdf/HowPeople.pdf

MARGULYS, Lynn; SCHWARTZ, Karlene V.; DOLAN, Michael. Diversity of life: the illustrated guide to the five kingdoms. Boston: Jones and Bartlett Publishers, 1999.

MAUSS, Marcel. Sociologia e Antropologia. São Paulo: EPU \& EdUSP, V.2, 1974.

MORIN, Edgar. O homem e a morte. Sintra: Publicações Europa-América, 1976.

MORSE, Richard M. O espelho de Próspero. Cultura e Idéias nas Américas. São Paulo, Companhia das Letras, 1988.

MILTON, Kay. Anthropomorphism or egomorphism? The perception of non-human persons by human ones. In: KNIGTH, John (ed.). Animal in person. Cultural perspectives on humananimal intimacies. Oxford: BERG, 2005, pp. 255-271.

MULLIN, Molly. Mirrors and windows: sociocultural studies of human-animal relationships. Annu. Rev. Anthropol. 28: 201-224, 1999.

NOGUEIRA, Maria A. L. 2007. A casa e os devaneios do pertencimento. In: LEITÃO, L.; AMORIM, L. (orgs.). 2007. A casa nossa de cada dia. Recife: Ed. UFPE, pp. 71-84.

NORBERG-SCHULZ, Christian. Nuevos caminos de la arquitectura. Existencia, espacio y arquitectura. Barcelona: Editorial Blume, 1975, p. 7-45.

OSÓRIO, Andréa. Alguns aspectos simbólicos acerca do gato. ILHA, Florianópolis, 12(2): 231259, 2011.

PAQUOT, Thierry. Habitat, habitation, habiter. Ce que parler veut dire... Informations Sociales, 3(123): 48-54, 2005.

PEIRANO, Mariza. A Alteridade em Contexto: A Antropologia como Ciência Social no Brasil. Série Antropologia, 255, 1999, 35pp.

377-391, 2014. Etnografia não é método. Horizontes Antropológicos, Porto Alegre, 42(20):

PIEDADE, Hélia M. Fauna Urbana. São Paulo: SMA/CEA. (Cadernos de Educação Ambiental, 17), 2013.

RABINOW, Paul; ROSE, Nikolas. Biopower Today. BioSocieties, London,(1):195-217, 2006.

RICOEUR, Paul. O Si-mesmo como outro. São Paulo, Papirus, 1994.

REVISTA DE HISTÓRIA BIBLIOTECA NACIONAL. Dossiê Animais domésticos. Rio de Janeiro, $n^{\circ} 60,2010$.

ROCHA, Ana L. C. da. Antropologia das formas sensíveis: entre o visível e o invisível, a floração dos símbolos. Horizontes Antropológicos. UFRGS, Porto Alegre, (2):107-117, 1995.

ROCHA, Ana L. C. da e ECKERT, Cornelia. O tempo e a cidade. Porto Alegre: Ed. da UFRGS, 2005.

ROMESÍN, Humberto M.; GARCÍA, Francisco J. V. De máquinas e seres vivos. Autopoiese - a organização do vivo. Porto Alegre: Artes Médicas, 1997.

ROTHFELS, Nigel (ed.). Representing animals. Bloomington: Indiana University Press., 2002. RUSSEL, Nerissa. Navigating the human-animal boundary. Reviews in Anthropology, 39:3-24, 2010. 
SANSOT, Pierre. 1986. Les formes sensibles de la vie sociale. Paris, PUF.

SENNET, Richard. $O$ declínio do homem público. As tiranias da intimidade. São Paulo: Companhia da Letras, 1988.

SERPELL, James A. Domestication and history of the cat. In D. C. Turner \& P. Bateson (Eds.), The domestic cat: The biology of its behaviour. Cambridge: Cambridge University Press, 2000. p. $179-192$.

SERPELL, James. A. Anthropomorphism and Anthropomorphic selection-beyond the "Cute Response". Society and Animals, 10(4): 437-454, 2002.

SILVEIRA, Flávio L. A. da. A paisagem como fenômeno complexo, reflexões sobre um tema interdisciplinar. In: SILVEIRA, Flávio L. A. da; CANCELA, Cristina D. Paisagem e cultura: dinâmica do patrimônio e da memória na atualidade. Belém: EDUFPA, 2009a, pp. 71-83.

SILVEIRA, Pedro C. B. Híbridos na paisagem: uma etnografia nos espaços de produção e de conservação. Ambiente \& Sociedade, 1(18): 83-98, 2009b.

SIMMEL, Georg. Sociologia. In: FILHO, Evaristo de M. (org). São Paulo: Ática, 1983.

SIMMEL, Georg. A ponte e a porta; Filosofia da paisagem. In: MALDONADO, Simone C. (org.). Georg Simmel: sentidos, segredos. Curitiba: Appris, 2011, pp. 19-26; $28-42$.

SPIVAK, Gayatri Chakravorty. Can the Subaltern Speak?. In: NELSON, C.; GROSSBERGE, L. (Eds.). Marxism and the Interpretation of Culture. London: Macmillan, 1988, pp. 271 - 313.

STRATHERN, Marilyn. Parts and wholes. Refiguring relationship in a Post-Plural World. In: KUPER, Adam. (ed.). Conceptualizing society. Routledge: London and New York, 1992, 75104.

STRATHERN, Marilyn. No limite de uma certa linguagem. Entrevista a Eduardo Viveiros de Castro e Carlos Fausto. MANA, 5(2):157-175, 1999.

THIBAUD, Jean-Paul. La fabrique de la rue en marche : essai sur l'altération des ambiances urbaines. Flux, 66/67:111-119, 2006/4-2007/1.

THOMAS, Keith. O Homem e o Mundo Natural: mudanças de atitudes em relação às plantas $e$ aos animais (1500-1800). São Paulo: Companhia das Letras, 1988.

TUAN, Yi-Fu. Espaço \& Lugar. A Perspectiva da Experiência. São Paulo: DIFEL, 1983.

VELDEN, Felipe V. Inquietas companhias. Sobre os animais de criação entre os Karitiana. São Paulo: Alameda, 2012.

VELHO, Gilberto. Projeto e Metamorfose: antropologia das sociedades complexas. Rio de Janeiro: Jorge Zahar Ed., 1994.

VIDAL, Denis. Anthropomorphism or sub-anthropomorphism? An anthropological approach to gods and robots. Journal of the Royal Anthropological Institute, 13, 2007, pp. 917-933.

VIVEIROS DE CASTRO, Eduardo. A inconstância da alma selvagem e outros ensaios de Antropologia. São Paulo: Cosac \& Naif, 2002.

ZUKIN, Sharon. Paisagens urbanas pós-modernas: mapeando cultura e poder. In: ARANTES, Antonio A. (org.). O espaço da diferença. São Paulo: Papirus, 2000.

WACQUANT, Loïc. Esclarecer o Habitus. EDUCAÇÃO \& LINGUAGEM, 10(16): 63-71, 2007. WHITE, Kara. And Say the Cat Responded? Getting Closer to the Feline Gaze. Society \& Animals, 21: 93-104, 2013.

WOLFE, Cary. Old orders for new: ecology, animal rights, and poverty of humanism. In: Animal rites. American culture. The discourse of species, and posthumanist theory. University of Chicago Press, 2003, pp. 11-43.

YARRI, Donna. Animals as kin: the religious significance of Marc Bekoff's work. Zygon, 1(41), 21-28, 2006.

\section{Fontes on-line}

Humanimalia: A Journal of Human/Animal Interface Studies www.depauw.edu/humanimalia http://www.paisagenshibridas.com.br

Recebido em: 25/10/2016. Aprovado em: 02/12/2016. 